\title{
RELACIONES IGLESIA-ESTADO. EL CONCORDATO DE 1753
}

\author{
POR
}

\author{
M. a Josefa MaRTíneZ JiMÉneZ \\ Universidad de Málaga
}

\begin{abstract}
RESUMEN
Estudio del Patronato Real en la época de Fernando VI por medio del referido concordato, en el que se describe la capacidad del rey para controlar la distri-
\end{abstract} bución de los nombramientos y los beneficios que se conceden.

\begin{abstract}
Study on the Royal Patronage in the Ferdinand VIth time, through the concordat, that describes the king's abilities to control the appointments and profit distribution that are granted.
\end{abstract}

Llama la atención que en un período de tiempo relativamente corto se produzcan varios concordatos entre la Corona española y la Santa Sede. Unos los firma el rey Felipe V y otro, el que nos ocupa, Fernando VI. Abordamos el estudio de este tema con el deseo de conocer los términos en que se trata la cuestión del Patronato Real, eje de este encuentro entre la Corona y el papado.

El presente trabajo intenta acercarse al estudio del Concordato como documento que permite aquilatar la trascendencia que su aplicación supuso para la Corona, como Patrono Real en las iglesias de su reino, y la capacidad de distribución y control sobre los nombramientos y beneficios. Para ello analizaremos el documento y otros colaterales como epistolas y ratificaciones del Papa y el Rey.

La metodología que vamos a utilizar va a ser el análisis de los documentos objeto del estudio, sacados del Archivo de la Catedral de Málaga, donde se encuentra una copia de los mismos. 
El derecho internacional presenta múltiples vías de encuentros, acuerdos, compromisos, donde los estados pueden dilucidar conflictos y consensos de todo tipo. El Vaticano, en cuanto estado, se ve inmerso en estas fórmulas para legitimar acuerdos con otros países, y el Concordato es una de las vías que usa el Vaticano, cuando el asunto a tratar tiene gran relieve e importancia, como medio para llegar a entendimientos en el campo de las relaciones internacionales. Con la monarquía española, la Santa Sede articula una serie de negociaciones en torno al Patronato Real ${ }^{1}$. El concordato fue un medio útil, que se aplicó en varias ocasiones, la última con Felipe V. Este monarca llegó a firmar dos concordatos. Con el primero se intentan reanudar las relaciones entre la Iglesia y el Estado, bastante deterioradas después de reconocer el papa Clemente XI al archiduque Carlos como aspirante al trono español (expulsión del Nuncio y cierre de la nunciatura). Las negociaciones se abren una vez reconocido, en Utrech, Felipe V rey legítimo de Espafía y, por tanto, Patrono Real. La nueva situación obliga a reanudar las negociaciones entre los representantes de la Corona y el papado : José Rodriguez Villalpando, marqués de la Compuesta y el auditor Pompeyo Aldobrandi. Las negociaciones culminan con el Concordato de 17-VI-1717. Quizás éste tuvo un carácter provisional sobre aspectos en litigio, como el Patronato Real. Las negociaciones vuelven a romperse y las relaciones papado Corona van a ser muy difíciles a lo largo del reinado de Felipe V. Se firma un nuevo Concordato el 26- 9- 1737 entre los cardenales Firrao y Troyano Acquaviva,para restablecer la paz entre Clemente XII y Felipe V, pero no se consigue lo que el monarca pretende: el Real Patronato Universal.

\section{ORígenes del Patronato Real}

La gestación del Patronato Real al que perteneció la Iglesia de Málaga va a estar intimamente unida a las guerras de Reconquista, pues va a ser en estas fechas, comienzo de la guerra de Granada, cuando los Reyes Católicos empiezan a negociar una serie de acuerdos con la Santa Sede. Los acuerdos contienen concesiones de algunos privilegios pontificios, que van a tener un carácter de extraordinarios y, a la vez, van a ser estables. Esta fórmula ya la había empleado la Santa Sede con la monarquía portuguesa ${ }^{2}$, incluso con la propia Corona Castellana. Tenemos un antecedente en una bula otorgada por el Papa Eugenio IV, el 24 de Junio de 1436, a Juan II de Castilla, concediéndole privilegios a él y

\footnotetext{
I J. MARTtNEZ JIMÉNEZ, «Relaciones entre la Monarquía y la Iglesia Malaguefia en el s. XVIII", Monarquia y pueblos en la Espah̆a Maderna, Alicante, 1997.

2 V. González SÁnchez, Málaga: Perfiles de su historia en documentos del Archivo Catedral (1487-1516), Málaga, 1994.
}

Actas del I Congreso de Historia de la Iglesia y el Mundo Hispánico Hispania Sacra, $\$ 2$ (2000) 
a sus sucesores. De nuevo recurre la Santa Sede a este cauce que va a posibilitar un amplio campo de implicación real en competencias eclesiales, pero que, a su vez, requieren en la misma medida unos compromisos, entre los cuales está el de fundar todas las iglesias que sean necesarias en todas las ciudades que se van ganando al reino de Granada. Con la fundación, la Corona queda obligada a edificar y a dotar de todo lo necesario para el culto de las nuevas iglesias. Los fondos necesarios para las dotaciones proceden, según Benassar, de los bienes pertenecientes a las mezquitas. De ellos salió la dotación para crear el arzobispado de Granada y los obispados de Málaga, Almería y Guadix ${ }^{3}$.

Como contrapartida, la Corona espafiola tiene la potestad de presentar a las personas para ocupar cargos eclesiásticos como obispados, prebendas catedralicias, beneficios parroquiales y otros cargos de menor rango. El Patronato Real de Granada vio la luz en $1486^{4}$, y, como consecuencia, para llevar a cabo la práctica cotidiana de estos acuerdos, se va a generar necesariamente una relación directa y permanente entre la Iglesia y la Corona, donde sustancialmente se van a emplear como medio las epístolas.

Sin embargo, el preámbulo a las negociaciones sobre el Patronato no está exento de alguna tensión, como afirman autores como el profesor Suberbiola ${ }^{5}$. Éste distingue dos periodos posteriores a 1486 que dan paso a la restauración de las cuatro diócesis del reino de Granada.

El primero lo enmarca entre los años 1487-1488, en el que paralelamente a las guerras de reconquista se tuvo que hacer frente al arzobispado de Sevilla en su deseo de Expansión (Ronda y Antequera) y control de todo el territorio andaluz. Si bien, al final, se establecen los límites entre Málaga y Sevilla.

El segundo período, de la misma duración (1492-1493), discurre en una línea más conciliadora que el anterior; seguramente en esto tuvo mucho que ver la victoria real en la conquista de Granada.

La Iglesia de Sevilla acepta la decisión regia de dividir la provincia Bética en dos arzobispados: el hispalense y el de Granada. Bajo la metropolitana de Granada quedan las diócesis de Guadix y Almería, mientras que Málaga, a pesar de formar parte del Real Patronato de Granada, sigue adscrita al arzobispado de Sevilla. Así, con esta sutil fórmula, se alcanzaron los objetivos reales.

La Bula original pontificia de Inocencio VIII, Ortodoxae Fidei (13-12-1486) para la erección de la Santa Iglesia Catedral de Málaga, parece ser que no se

\footnotetext{
${ }^{3}$ B. Benassar, La España del siglo de oro, Barcelona, 1983.

4 V. Gonzal.rz SANCHEZ, op. cit.

5 Suberbiola Martinez, Real patronato de Granada. El Arzobispo Talavera, la Iglesia y el Estado Moderno (1486-1516), Granada, 1983.
} 
guardó entre los fondos de su archivo, según nos dice Ángel Riesco ${ }^{6}$; pero sí estuvo en el documento original de la ejecutoria de erección de la Iglesia principal de la diócesis y la institución de sus oficios y beneficios. La ejecutoria estaba acompañada de una copia notarial de la citada bula. En los archivos de las restantes diócesis que comprendía el Patronato, tampoco estuvo la Bula. A esta situación aparentemente extraña, el profesor Riesco le encuentra una explicación: la Cancillería pontificia la envió a los Reyes Católicos, en consideración a su devoción, a que eran reyes cristianos y a su proyecto de expansión de la fe a todos los territorios de sus reinos. El Papa también asigna la tutela y desarrollo de esta Bula a dos comisarios elegidos entre la jerarquía eclesiástica. El primero fue el Cardenal de España, D. Pedro González de Mendoza, Arzobispo de Toledo, y el segundo, D. Diego Hurtado de Mendoza, Arzobispo de Sevilla. Con esta elección reciben plena libertad para llevar a cabo el encargo papal.

Fernando VI, hombre piadoso, continúa como rey con el sello pacificador que mantienen en general sus actuaciones y asi se muestra dispuesto a abordar, sin reparos, algunos asuntos que habían quedado sueltos en el anterior Concordato de 1737, entre el Papa Clemente XII y el rey Felipe V. El nuevo Concordato de 1753 es conducido por personas cercanas al rey Fernando VI, como su confesor, el jesuita Francisco Rávago, quien tuvo una gran influencia sobre el monarca, especialmente en todo lo concerniente al Patronato Real, donde dirige y aconseja al rey, pasando las fronteras del confesionario ${ }^{7}$. Es importante también la aportación del Marqués de la Ensenada, quien presenta al rey un estudio en el que entre otras cosas aconseja al monarca la relación a seguir con Roma y la Iglesia de España y, por último, Ventura Figueroa, auditor de la Rota. Los tres hicieron posible la firma del concordato, gracias a la energía del Marqués de la Ensenada, el tesón del padre Rávago y la astucia de Ventura Figueroa.

Una copia del concordato hecha en Madrid por orden del rey en el año de 1763, en la imprenta de Antonio Pérez de Soto, se envía al cabildo de la iglesia catedral de Málaga, donde pasa a engrosar los fondos documentales del archivo catedralicio. La copia del concordato llega acompañada de una carta del rey, fechada el 16 de marzo de 1753 en el Buen Retiro. En la carta, el rey, a través de un texto conciso, pone en conocimiento del cabildo malagueño el documento que envía, el concordato, y el asunto que se dilucida en el documento «sobre la antigua controversia del Regio Patronato Universal». Finalmente manda que el documento quede archivado en el cabildo y se despide de forma protocolaria.

${ }^{6}$ A. Riesco Terrero, Erección Canónica de las Cuatro Catedrales del Reino de Granada, Universidad de Málaga, Málaga, 1987.

${ }^{7}$ AlCaraz GómeZ, Jeswitas y Reformismo.

Actas del 1 Congreso de Historia de la Iglesia y el Mundo Hispánico Hispania Sacra, 52 (2000) 


\section{ANÁLISIS DEL CONCORDATO}

El documento se redacta en un lenguaje solemne y culto sembrado de términos técnicos. La estructura que presenta el documento es la siguiente: una introducción, una presentación de los asuntos a tratar y las determinaciones tomadas que se desarrollan a lo largo de ocho apartados.

\section{Introducción y motivo del documento}

Expresa el deseo que el Papa ha tenido y tiene en mantener una cordial correspondencia entre el Vaticano y la piadosa nación española con sus católicos reyes. Relata a continuación los numerosos intentos de acercamiento que ha provocado la Santa Sede para buscar consenso sobre los puntos en discordia, representada por los difuntos cardenales Belluga y Acquaviva. El Papa incluso mandó un escrito donde explica las intenciones de la Santa Sede sobre el Patronato Real. Los resultados no fueron los esperados, pues en lugar de abrir caminos, se multiplicaron las controversias, que provocaron el resurgir de asuntos que se creían olvidados. Llega a decir que temió en algún momento la ruptura de las negociaciones con un desenlace nefasto para ambas partes. El Papa resalta la disposición favorable del rey para buscar el entendimiento «piadosa propensión del ánimo del rey Fernando VI (...) a un equitativo y justo temperamento sobre las diferencias promovidas") y precisa que los acuerdos serán firmados por los Procuradores y Plenipotenciarios de ambas partes siguiendo las normas de este tipo de acuerdos.

\section{Introducción de los temas a tratar}

A continuación el Papa va presentando los temas siguiendo un orden creciente, según la complejidad de cada uno. Primero se hace eco de las necesidades que demanda el rey acerca de la observancia de la disciplina en el clero secular y regular «necesidad que hay en las Españas de reformar en algunos puntos la Disciplina de Clero Secular y Regular». El Papa responde y dice que se hará todo lo establecido sobre normas de vida del Clero en los Sagrados Cánones, en las Constituciones Apostólicas y en el Santo Concilio de Trento, e invita al Clero español a leer la bula sobre el tema Apostolici Ministerij. Después se comienza a plantear el tema central del documento. Aquí el Papa reconoce a los reyes españoles lo siguiente:

- A los Reyes Católicos de las Españas pertenece el Real Patronato, lo que faculta al rey para nominar a los Arzobispados, Obispados, Monasterios y 
Beneficios Consistoriales, registrados y tasados en los Libros de Cámara cuando se producen vacantes en el reino. Esta potestad del rey la defiende la Corona con todos los documentos que la avalan: Bulas, Privilegios Apostólicos y otros títulos.

- La potestad del rey de España sobre las nominaciones a los Arzobispados, Obispados y Beneficios que quedan vacantes en los Reinos de Granada y de las Indias.

- La potestad real de nómina sobre algunos otros beneficios en caso de producirse vacante en ellos. En este punto se acuerda que en los casos de nombramiento de Arzobispados, Obispados, Monasterios y Beneficios Consistoriales deben continuar recibiendo la expedición de las respectivas Bulas en Roma. De esta manera permanecen sin cambio.

El desacuerdo importante surge acerca de los nombramientos a los Beneficios residenciales y șimples que hay en el reino espafiol. Éste es el nudo principal de los asuntos a tratar en el Concordato y sobre el que no hay consenso. El documento lo presenta diciendo:

- Los Reyes de Espafía pretenden, en virtud del Patronato Universal, nominar los Beneficios residenciales y simples de todos los reinos de Espafia en caso de vacante, excepto los del Reino de Granada y las Indias, que ya lo tienen.

- La Santa Sede argumenta las razones de libertad que tiene sobre estos Beneficios, y su colación en los meses Apostólicos, en los casos de reserva y respectivamente, la de los ordinarios en sus meses. Tras una extensa disputa sobre este asunto, alcanzan el siguiente acuerdo:

a) Su Santidad el Papa Benedicto XIV se reserva la potestad de libre y privativa colación a perpetuidad en su persona y la de sus sucesores sobre 52 Beneficios.

b) Esta potestad de Su Santidad y sucesores posibilita poder premiar y proveer a eclesiásticos españoles por diversas causas: por probidad, integridad de costumbres, insigne literatura, servicios hechos a la Santa Sede.

c) La Colación de los 52 Beneficios será siempre privativa de la Santa Sede en cualquier mes, en cualquier momento que vaquen, aunque ésta se produzca de resulta real, incluso aunque alguno de estos Beneficios esté en el Real Patronato de la Corona o situados en diócesis donde algún Cardenal tenga amplio indulto de conferir. En este último caso no se debe

Actas del I Congreso de Historia de la Iglesia y el Murdo Hispánico Hispania Sacra, 52 (2000) 
actuar jamás en perjuicio de la Santa Sede ni atender ninguna excepción que menoscabe la autoridad Papal.

d) Las Bulas de los 52 Beneficios se expedirán en lo sucesivo siempre en Roma, con la obligación de pagar los acostumbrados emolumentos correspondientes a la Dataria y Cancillería Apostólica.

e) Todo lo que comprende la potestad del Papa queda sin imposición de pensión ni exigencia de Cédulas Bancarias.

A continuación registra los nombres de los 52 Beneficios para evitar equívocos sobre la identidad de los beneficios que componen este grupo en un futuro. La relación es la siguiente:

En la catedral de Ávila, el Arcedianato de Arévalo.

En la de Orense, el Arcedianato de Bubal.

En la de Barcelona, el Priorato antes Secular, ahora Regular de la Colegiata de Santa Ana.

En la de Burgos, la Maestrescolia, y el Arcedianato de Palenzuela.

En la de Calahorra, el Arcedianato de Naxera y la Tesorería.

En la de Cartagena, la Maestrescolia y en su diócesis el Beneficio simple de Albacete. chite.

En la Catedral de Zaragoza, el Arzjprestazgo de Daroca y el Arciprestazgo de Bel-

En la de Ciudad-Rodrigo, la Maestrescolia.

En la de Santiago, el Arcedianato de la Reina: el Arcedianato de Santa Tesia y la Tesorería.

En la de Cuenca, el Arcedianato de Alarcón y la Tesoreria.

En la de Córdoba, el Arcedianato de Castro, y en su diocesis el Beneficio simple de Belalcazary el Préstamo de Castro y Espejo.

En la Tortosa, la Sacristía y la Hospitalaria.

En la de Gerona, el Arcedianato de Ampurdán. nilla.

En la de Jaen, el Arcedianato de Baeza y en su Obispado el Beneficio simple de Arjo-

En la Lérida, la Preceptoría.

En la de Sevilla, el Arcedianato de Jerez y en su diócesis el Beneficio simple de la Puebla de Guzmán y el préstamo de la Iglesia de Santa Cruz de Écija ${ }^{8}$.

En la de Mallorca, la Preceptoria y la Prepositura de San Antonio de Santo Antonio Vienense.

${ }^{8}$ Nota: en lugar de este Préstamo de Santa Cruz de Écija, que antes del Concordato estaba unido perpetuamente a la Iglesia Colegial de Lerma, se subrogó y reservó en el afo de 1757 a la libre y perpetua Colacion de la Santa Sede uno de los tres Beneficios simples servideros de la Iglesia de Santa María de la Ciudad de Alcalá la Real.

Actas del I Congreso de Historia de la Iglesia y el Mundo Hispánico Hispania Sacra, 52 (2000) 
Nullius, en el Reino de Toledo, el beneficio simple de Santa María de la Ciudad de Alcalá la Real ${ }^{9}$.

En el Obispado de Orihuela, el beneficio simple de Santa Maria de Elche.

En la Catedral de Huesca, la Chantría.

En la de Oviedo, la Chantría.

En la de Osuna, la Maestrescolía y la Abadía de San Bartolomé.

En la de Pamplona, la Hospitalaria, antes regular, ahora Encomienda y la Preceptoria general de Olite.

En la de Plasencia, el Arcedianato de Medellín y el de Trujillo.

En la de Salmanca, el Arcedianato de Monleón.

En la de Siguienza, la Tesorería y la Abadía de Santa Coloma.

En la de Tarragona, el Priorato.

En la de Tarazona, la Tesorería.

En la de Toledo, la Tesorerfa y en su diócesis el Beneficio simple de Ballecas.

En la Diócesis de Tuy, el Beneficio simple de San Martín de Rosal.

En la Catedral de Valencia, la Sacristía mayor.

En la de Urgel, el Arcedianato de Andorra.

En la de Zamora, el Arcedianato de Toro.

\section{Determinaciones tomadas}

Para que queden bien ordenadas las Colaciones, Presentaciones, Nominas e Instituciones de los Beneficios, se plantean todas las posibles implicaciones de jurisdicción, autoridad, costumbres etc. que intervienen en los Beneficios que queden vacantes en el futuro en el reino de Espaffa. Se articula y acuerda por ambas partes una normativa pormenorizada a lo largo de ocho puntos, donde se plantean todas y cada una de las circunstancias que resulten de las Concesiones.

\section{Primer apartado}

En general fija la situación en que queda la autoridad eclesiástica en su capacidad para proveer y otorgar Beneficios. Atendiendo a la posibilidad de proveer, se dice que los Arzobispos, Obispos y Coladores provean como lo han hecho en el pasado, siempre que las vacantes se produzcan en los meses ordina-

${ }^{9}$ Nota: es uno de los tres Beneficios que hay en esta Iglesia.

Actas del I Congreso de Historia de la Iglesia y el Mundo Hispánico Hispania Sacra, 52 (2000) 
rios de Marzo, Junio, Septiembre y Diciembre, aunque en ese momento esté vacante la Silla Apostólica. Atendiendo a la posibilidad de presentar los Patronos Eclesiásticos los Beneficios de su Patronato, continúan sin cambios; se excluyen las alternativas de meses anteriormente nombrados en las Colaciones que en el pasado se daban y no se volverán a hacer en el futuro.

\section{Segundo apartado}

Reafirma lo establecido sobre las Prebendas de Oficio que se vienen cubriendo por oposición y concurso abierto. Al proveerlas en el futuro, se continuarán haciendo de igual forma sin modificar absolutamente nada. Esto es extensible a los Beneficios de Patronato laical de Particulares, donde tampoco se innovará nada.

\section{Tercer apartado}

Prosigue este apartado con la supervisión de Beneficios que requieren superar una oposición y dice que las Parroquias y Beneficios Curados se continúen dando como en el pasado: por concurso oposición, cuando queden vacantes no sólo en los meses ordinarios, sino también (ésta es la innovación), cuando queden vacantes en los meses y casos de las reservas, aunque la presentación pertenezca al Rey (Patronato Real). En estos casos es necesario que el Patrono elija unos de los tres considerados idoneos por los Examinadores Sinodales (ad Curam animarum) y lo presente al Ordinario.

\section{Cuarto apartado}

Reitera la inmovilidad del Derecho de los Patronos Eclesiásticos a presentar los Beneficios de sus Patronatos en los cuatro meses ordinarios. También recuerda y ordena que se mantenga la costumbre de algunos Cabildos, Rectores, Abades y Cofradías que tienen autoridad Eclesiástica, de recurrir a la Santa Sede para que las elecciones hechas por ellos sean confirmadas con Bula Apostólica.

\section{Quinto apartado}

Este apartado introduce el tema central del Concordato (Patronato Real Universal). Comienza recordando los Beneficios que han quedado bajo la jurisdic- 
ción Papal de manera intocable, como son los 52 Beneficios de libre Colación para la Santa Sede, junto a los Beneficios y circunstancias especificadas en los apartados anteriores. Salvados todos ellos, entra de lleno en el punto central objeto de discordia. Acuerda que la Majestad del Rey Católico y los Reyes sucesores tienen perpetuamente el derecho universal de nombrar y presentar (indistintamente en todas las Iglesias Metropolitanas, Catedrales, Colegiatas y Diócesis de los Reinos de las Espafias, que actualmente posee, a las Dignidades mayores post Pontificalem, y otras en Catedrales, y Dignidades Principales, y otras en Colegiatas, Canonicatos, Porciones, Prebendas, Abadias, Prioratos, Encomiendas, Parroquias, Perfonatos, Patrimoniales, Oficios, Beneficios Eclesiasticos, Seculares, y Regulares.... de qualquier naturaleza que sean, que al presente existen, y que en adelante se fundareny. Respecto a las nuevas fundaciones, quedarían fuera de la potestad real, si los nuevos fundadores se reservan para sí y sus sucesores el derecho de presentar en todos los territorios que en el momento comprende el reino de España, con la salvedad de los casos generales antes expuestos, como los casos de reservas generales y especiales, los comprendidos en los Meses Apostólicos. A éstos también se unen los Beneficios que quedan vacantes en los meses ordinarios y coinciden con la vacante de sillas Arzobispales y Obispales.

La Santa Sede cede los derechos que tiene en el reino de España de otorgar Beneficios por sí o por medio de la Dataría, Cancillería Apostólica, Nuncios de España, e Indultarios al Rey Católico y sus sucesores en la Corona. De esta manera, el Rey obtiene el Derecho universal a los referidos Beneficios en todo el territorio del reino de España

con las facultades que ya posee en el Patronato Real. Como consecuencia, ningún Nuncio Apostólico, ningún Cardenal, ningún Obispo de España puede conceder Beneficios en los meses Apostólicos sin permiso expreso del Rey o sus sucesores.

\section{Sexto Apartado}

Este apartado articula las facultades anteriormente citadas concedidas al Rey con salvaguardar intacta la autoridad de los Obispos, aunque los Beneficios vacantes procedan de provisiones Reales. Por tanto, todos ellos deben recibir las Instituciones y Colaciones Canónicas de sus respectivos Ordinarios y no necesitan expedición de Bulas Apostólicas.

En el último punto se contemplan excepciones, como la referida a la confirmación de las Elecciones anteriormente citadas, en los casos en que los presentados o nombrados, bien por cuestión de edad u otro impedimento canónico, 
necesiten alguna dispensa o gracia Apostólica, u otra cosa superior a la autoridad ordinaria de los Obispos. En todos estos casos se debe recurrir siempre en el futuro a la Santa Sede y se han de pagar a la Dataría y cancillería Apostólica los emolumentos acostumbrados sin imposición ni exigencias de Pensiones ni Cédulas Bancarias.

\section{Séptimo Apartado}

En este apartado se clarifica hasta dónde puede llegar la autoridad real como Patrono y, con mucho tacto, se defiende la jurisdicción sobre territorios y personas de la jerarquía eclesiástica. Se especifica que la concesión y subrogación al Monarca español en los derechos de nómina, Presentación y Patronato no se confunda con una transacción al Rey y sucesores de ninguna Jurisdicción Eclesiástica sobre las Iglesias que abarquen esos derechos ni sobre las personas que presente y nombre. En consecuencia, todo el personal eclesiástico tanto los pertenecientes al Patronato Real, los otorgados por la Santa Sede y los 52 Beneficios reservados, quedan sujetos a sus respectivos Ordinarios y, por encima de ellos, a la autoridad del Pontifice Romano que, como Pastor, tiene siempre sobre las Iglesias y personas eclesiásticas. También affade este apartado la responsabilidad y prerrogativa de dar protección especialmente a las Iglesias del Patronato Real.

\section{Octavo Apartado}

Este apartado muestra las compensaciones económicas a la Santa Sede, acordadas tras las cesiones hechas a los Reyes de España en razón del Patronato. Roma expone que después de estas cesiones, la Dataría y Cancillería Apostólica, quedan sin realizar la utilidad de las Expediciones y Annatas. La nueva situación provoca una merma importante en los ingresos del erario pontificio. Traducido al lenguaje de las cifras, supone al Rey pagar al Papa, en una sola vez, la cantidad de 310.000 ducados romanos. Dicha cantidad a un interés de un $3 \%$ produce una ganancia anual de 9.300 escudos romanos.

Sobre la imposición de pensiones y exigencia de cédulas bancarias, objeto de constantes disputas, una vez abolidas en el documento, se plantea el problema económico que ocasiona la supresión de estos ingresos a la Santa Sede. El problema radica en las dificultades para pagar a los ministros, que ejercen sus funciones en los negocios propios del gobierno de la Iglesia universal. El documento resalta la buena voluntad del Rey en su deseo de ayudar y socorrer al 
Papa. El Rey queda obligado por este concepto a pagar la cantidad de 600.0000 escudos romanos, con un interés del $3 \%$ que produce anualmente la cantidad de 18.000 escudos. De esta manera, queda prohibido el uso en el futuro de la imposición de las pensiones y la exigencia de cédulas bancarias, con excepción de las aprobadas hasta el momento.

Se ajustan algunas provisiones particulares que venían siendo también objeto de discordia, como las hechas por la Santa Sede en las catedrales de Palencia y Mondoñedo. El Rey acepta que los provistos entren en posesión después de la ratificación del presente Concordato.

Otra cuestión pendiente se centra en los espolios y frutos de las Iglesias Obispales vacantes, que eran objeto de disputa con la nunciatura y la Cámara Apostólica, en cuanto al uso, dependencias y ejercicio sobre ellos. El Papa anula todo tipo de acuerdos ( Constituciones Apostólicas, Concordias etc.) que sobre este asunto se hayan hecho en el pasado entre la Cámara Apostólica y los Obispos, Cabildos, Diócesis, etc. Las ganancias de estos frutos se derivan en el futuro a usos píos establecidos en los Sagrados Cánones. Este acuerdo entra en vigor el mismo día de la ratificación del Concordato. Implica también el acuerdo que en el futuro ninguna persona eclesiástica puede testar los frutos y espolios de sus Iglesias Obispales, ni aun dedicándolos a usos píos. Sobre este asunto, el Rey puede intervenir para elegir en el futuro los Ecónomos y Colectores entre personal eclesiástico,y tiene la facultad de administrar y emplear los frutos para el uso acordado. Como contrapartida el Rey entrega a Roma la cantidad de 233.333 escudos, que con un interés del $3 \%$ generan 7.000 escudos anuales. También deberá disponer el Rey 5.000 escudos anuales en Madrid para la subsistencia de los Nuncios Apostólicos y así compensar la pérdida de los frutos de las iglesias vacante.

Por último, encontramos las promesas de cumplir todo lo acordado y la manifestación de que el Concordato entra en vigor una vez entregadas las cantidades registradas y se ratifique el documento.

Firman el Concordato los representantes plenipotenciarios, en el palacio del Quirinal el 11 de enero de 1753, el Cardenal Valenti y Manuel Ventura Figueroa. 